\title{
Numerical experiment research on failure characteristics of anchored rock with negative Poisson's ratio bolt
}

feng chen ( $\nabla$ clucky@sina.cn )

Liaoning Technical University

Yanhong Du

Liaoning Technical University

manchao he

China University of Mining and Technology

xiaoming sun

China University of Mining and Technology

tianhui ma

Dalian University of Technology

\section{Research Article}

Keywords: rock engineering, negative Poisson's ratio, bolt, RFPA

Posted Date: March 12th, 2021

DOI: https://doi.org/10.21203/rs.3.rs-144456/v2

License: (c) (1) This work is licensed under a Creative Commons Attribution 4.0 International License. Read Full License 


\section{Abstract}

With the continuous increase of mining depth and engineering burying depth, the nonlinear physical and mechanical phenomena exhibited by rock are also more complicated. The load value often exceeds the yield strength of the traditional Poisson's ratio supporting materials, causing the supporting body to fail. Therefore, the bolt still needs to further in-depth research on new materials. In this paper, the rock model with a negative Poisson's ratio bolt had been established, the material properties of negative Poisson's ratio and the working principle of RFPA software were introduced, and RFPA software was used to study the reinforcement effect of negative Poisson's ratio bolt on the rock. The numerical experiment results show that, compared with the positive Poisson's ratio bolt, the negative Poisson's ratio bolt can significantly increase the bearing capacity of anchored rock, enhance the friction between the bolt body and the surrounding rock, and limit the rock movement. The anchored rock with negative Poisson's ratio bolt can absorb more energy. Negative Poisson's ratio material is one of the future development directions of bolt material.

\section{Introduction}

Bolt is a kind of supporting body that transmits tensile load to the stable rock layer to improve the stability and strength of the rock medium, bolt has a lower cost in terms of material and manpower, so it has been widely used in mining, transportation, water conservancy and urban underground space engineering [1-4]. With the development of rock anchoring problems in the direction of "large, deep and difficult", sudden engineering disasters and major malignant accidents caused by nonlinear large deformation damage have occurred frequently in recent years. The reason for these problems is that the traditional supporting materials including traditional bolts, anchor cables, U-shaped steel brackets and other traditional supporting materials frequently fail [5-6]. One of the root causes is that the materials of these supporting bodies belong to the traditional Poisson's ratio materials, i.e. plastic hardening materials, which instantly reach the yield strength and lose the bearing capacity under a large load, leading to failure of the support [7-10].

The Poisson's ratio $v$ is first discovered and proposed by French scientist Poisson (Simon Denis Poisson, 1781-1840). Poisson's ratio is also called the transverse deformation coefficient, which refers to the absolute value of the ratio of the transverse normal strain to the axial normal strain when the material is subjected to uniaxial tension or compression. It is the elastic constant reflecting the material transverse deformation. Expressed

by the formula as $v=\left|\varepsilon^{\prime} / \varepsilon\right|$ ( $\varepsilon^{\prime}$ is transverse normal strain, $\varepsilon$ is axial normal strain). Common materials

shrink in the vertical cross-sectional direction when they are stretched (see Fig. 1a), but expand in the direction

perpendicular to the section when they are compressed by external force. It is generally considered that almost all materials have a positive Poisson's ratio, such as the Poisson's ratio of rock is generally 0.2 to 0.3 , wood (along grain) is 0.05 , concrete is 0.16 to 0.18 , and alloy steel is 0.25 to 0.30 [11]. 
According to thermodynamic theory, the Poisson's ratio of isotropic material ranges from - 1 to 1 , so there are negative Poisson's ratio materials in theory $[11,12]$. Lakes was the first to obtain a new type of material of a concave unit structure with a Poisson's ratio -0.7 in a series of treatments of ordinary polyurethane foam in 1987 [13]. This also means that when the material is subjected to axial tension, it will occur lateral expansion deformation (see Fig. 1b). This kind of auxetic behavior greatly improves the material mechanical properties such as shear modulus, fracture toughness, energy absorption and indentation resistance. In addition, negative Poisson's ratio materials have a good stress dispersion effect, a very high shear modulus and a very low bulk modulus [14-17]. Because negative Poisson's ratio materials have stronger physical and mechanical properties than positive Poisson's ratio materials, they can be identified as structural materials and functional materials at the same time. Therefore, they have broad application space in the fields of biomedicine, automobile industry, textile, human body protection and national defense technology [18-20].

Figure 1. The deformation of axial tension material

Because the physical and mechanical parameters of different experimental samples have a certain degree of discreteness, it is basically impossible to change only one physical and mechanical parameter of the experimental sample while keeping other physical and mechanical parameters the same in indoor and outdoor comparative experiments [21, 22]. However, the numerical experiment method can be used to quickly adjust the parameters, and load in various directions can be applied arbitrarily, so that only one parameter can be changed under the condition that other parameters remain unchanged, so as to ensure the accuracy of the comparison results. In addition, the numerical experiment method adopted in this paper can take into account the heterogeneity of the rock and the complex stress conditions, so this method has strong applicability.

Based on the special mechanical properties of negative Poisson's ratio material, as well as the advantages of numerical experiment method, we used RFPA software to study the failure characteristics of anchored rock with negative Poisson's ratio bolt. The similarities and differences of stress, displacement and acoustic emission (AE) of anchored rocks with positive Poisson's ratio bolt and negative Poisson's ratio bolt had been compared and analyzed.

\section{Negative Poisson'S Ratio Material Properties}

Since Dr. Lakes first pointed out in 1987 that a material with a cellular structure can produce negative Poisson's ratio during deformation, a large number of negative Poisson's ratio materials and structures have been discovered, synthesized and prepared, ranging from molecular microscopic scale to macro structure scale [23-27]. Figure 2 shows negative Poisson's ratio materials at different scale levels. The structure of negative Poisson's ratio materials is also diverse, including negative Poisson's ratio foam structure, concave porous solid structure, microscopic negative Poisson's ratio structure, negative Poisson's ratio composite structure, etc. [28-31]. In recent years, a large number of Poisson's ratio materials/structures have been discovered and prepared. According to the current research results, 
negative Poisson's ratio materials/structures can be divided into two categories: natural materials and artificial materials, as shown in Table 1 [18].

Table 1

Classification of negative Poisson's ratio materials

\begin{tabular}{|c|c|}
\hline Types & Material name \\
\hline \multirow{3}{*}{$\begin{array}{l}\text { Natural } \\
\text { materials }\end{array}$} & Pyrite, monocrystalline materials such as arsenic and \\
\hline & Cadmium, natural silicate dips-quartz, stripa granite, \\
\hline & avesta gneiss, the skin of cats, salamanders, some cancellous bone of human leg \\
\hline \multirow{3}{*}{$\begin{array}{l}\text { Artificial } \\
\text { materials }\end{array}$} & Wedge-shaped graphite block, in-concave cell structure \\
\hline & polyester foam, teflon, ultra high molecular weight \\
\hline & Polyethylene, metal foam composite material, nylon and polyester \\
\hline
\end{tabular}

Figure 2. Negative Poisson's ratio materials at different scale levels

Negative Poisson's ratio material can improve the service performance of the structure by designing the mechanical properties of the structure $[26,30]$. The elastic properties of material can be expressed by four elastic constants in elastic theory, namely Young's modulus $E$, shear modulus $G$, bulk modulus $K$ and Poisson's ratio $v$. These four constants are not independent of each other for isotropic material, they are related to each other by the following equation: $G=E /(2(1+v))$ and $K=E /(3(1-2 v)) \otimes$ Many materials require $G$ to be larger than $K$. If we change $v$ by changing the microstructure of the material under the condition that the $E$ of the material remains unchanged, we can change the values of $K$ and $G$. For example, when $v$ is reduced to -1 , a shear modulus that is much higher than a bulk modulus can be obtained. In other words, the material is not prone to shear deformation but prone to volume changes.

\section{Introduction To Rfpa Software}

In 1995, Professor Tang proposed a new numerical simulation software named RFPA (Realistic Failure Process Analysis) [32]. RFPA software is a numerical experiment tool that can simulate the progressive failure process of material. The calculation method of this software is based on finite element theory and statistical damage theory. This method has considered the non-uniformity of material properties and the randomness of defect distribution, and combined the statistical distribution assumptions of this material property into the numerical calculation method (finite element method). The elements which satisfy the given strength criterion are destroyed, so that the numerical simulation of the failure process of heterogeneous materials can be realized. Due to the unique calculation and analysis method of RFPA software, it can solve most problems that cannot be solved by other simulation software in geotechnical engineering.

RFPA software workflow is mainly completed by the following three parts [33-36]: 
Solid modeling and meshing. The user selects the element type (solid, support or cavity), defines the mechanical properties of the medium, and performs solid modeling and mesh generation.

Stress calculation. According to the boundary conditions and loading control parameters inputted by users, as well as the input element property data, the stiffness matrix is formed, and the finite element calculation results (stress, node displacement) are solved and output.

Element phase change. Perform phase change judgments on the results produced by the stress solver according to the phase change criteria, and then weaken or rebuild the phase change primitives, finally form the data files required for the iterative calculation of the stiffness matrix.

The entire workflow can be seen in Fig. 3. For each given displacement increment, RFPA software first perform stress calculation, and then check whether there are phase change primitives in the model according to the phase change criterion. If there is no phase change element, this software will continue loading to add a displacement component and proceed to the next step of stress calculation. If there is a phase change element, the stiffness will be weakened according to the stress state of the element, and then the stress calculation of the current step is performed again until no new phase change element appears. The above process is repeated until the applied load, deformation or macro fracture of the whole medium is reached. Full load is used for each step of the stress calculation and the calculation steps are independent of each other during the execution of the RFPA system.

Figure 3. RFPA software workflow picture

\section{Numerical Model}

In order to study the negative Poisson's ratio effect of the bolt, a numerical model has been established (see Fig. 4). The one-dimensional coordinate system is established along the axial direction of bolt for convenience of marking, and the origin 0 of the coordinate is located on the upper side of bolt. The overall size of the model is $2000 \times 1500 \mathrm{~mm}$, and the number of divided units is $400 \times 300$. The bottom side of this numerical model are fixed. Displacement compression load is applied to the left and right sides of the model, and the displacement increment is $0.002 \mathrm{~mm}$. The tensile load is applied to the upper end face of bolt, and the displacement increment is also $0.002 \mathrm{~mm}$. The bolt size is $1000 \times 20 \mathrm{~mm}$, which is located in the transverse middle of this model. Three points $A, B$ and $C$ are marked along the left boundary of the bolt to analyze the lateral displacement of the rock. The coordinates of the above three points along the axial direction of the bolt are $250 \mathrm{~mm}, 500 \mathrm{~mm}$ and $750 \mathrm{~mm}$ respectively. The physical and mechanical parameters of rock mass and bolt are shown in Table 2. At the same time, the numerical model of the bolt with positive Poisson's ratio is established. The Poisson's ratio of the bolt with positive Poisson's ratio is 0.3 , and the other physical and mechanical parameters are the same as that of the bolt with negative Poisson's ratio. The anchoring effect of two kinds of bolts is compared and analyzed. 
Table 2

Physical and mechanical parameters of the rock and bolt

\begin{tabular}{|lll|}
\hline Parameter & Rock & Bolt \\
\hline Inhomogeneous index & 2 & 200 \\
\hline Strength $(\mathrm{MPa})$ & 150 & 345 \\
\hline Young's modulus $(\mathrm{GPa})$ & 20 & 210 \\
\hline Poisson's ratio & 0.2 & 0.3 \\
\hline Density $\left(\mathrm{kg} / \mathrm{m}^{3}\right)$ & 2250 & 7800 \\
\hline Friction angle $\left(^{\circ}\right)$ & 55 & 30 \\
\hline
\end{tabular}

Figure 4. Numerical model

\section{Numerical Experiment Results \\ 5.1 Displacement change analysis}

As shown in Fig. 5, the displacements of points A, B, and C of anchored rock with negative Poisson's ratio bolt all increase linearly under the action of external force, the slopes of displacement curves are the same. As shown in Fig. 6, the displacement values of three points are 1.42932, 1.40181 and $1.40631 \mathrm{~mm}$ respectively after the negative Poisson's ratio bolt is broken. Under the action of external force, the displacements of points $A, B$, and $C$ of the anchored rock with positive Poisson's ratio bolt also show a linear increase, and the change trend of displacement curves is basically the same. The displacement values of three points are $0.42189,0.42212$ and $0.42112 \mathrm{~mm}$ respectively after the positive Poisson's ratio bolt is broken. Because the anchored rock with positive Poisson's ratio bolt ends the numerical experiment in loading step 168, the horizontal coordinates of the displacement and stress comparison curves of two anchored rock are taken to loading step 168. The displacements of points A, B and C of anchored rock with positive Poisson's ratio bolt are greater than those of anchored rock with negative Poisson's ratio bolt at any loading moment (see Fig. 6). This is because the positive Poisson's ratio material undergoes lateral contraction deformation, the surrounding rock can further deform toward the bolt body, while the negative Poisson's ratio material undergoes lateral expansion deformation, which limits the deformation of the surrounding rock to the bolt body and reduces the displacement of surrounding rock. The above numerical experiment results are in line with the actual situation, indicating that it is feasible and reliable to use numerical experiment methods to study this problem. In addition, the displacement differences of points $A, B$ and $C$ generally increase linearly, the maximum displacement differences of above three points is $0.00151,0.00279$ and $0.0012 \mathrm{~mm}$ (see Fig. 7).

Figure 5. Displacement curves of points A, B and C of anchored rock with negative Poisson's ratio bolt 
Figure 6. Displacement comparison curves of points A, B and C of two kinds of anchored rock before loading step 168

Figure 7. Displacement difference curve of points A, B and C of two kinds of anchored rock

\subsection{Stress analysis}

It can be seen from Fig. 8 that the bearing capacity of anchored rock with negative Poisson's ratio bolt reaches the maximum value of $378.2 \mathrm{MPa}$ in loading step 479 , this bolt is not damaged at this time (see Fig. 9a). When loading continues, the bearing capacity begin to drop, and then the bolt first breaks in the middle of bolt body at loading step 480 (see Fig. 9b).

The bearing capacity drops to $330.4 \mathrm{MPa}$ in the 486th step. Then the bearing capacity increases slightly and reaches the second peak of 349.7MPa. The other parts of bolt body are not damaged at this stage (see $9 \mathrm{c} \sim 9 \mathrm{~d}$ ). At the next loading step when the stress reaches the second peak, i.e. loading step 523 , the failure occurs successively at 5/8,6/8 and $7 / 8$ positions of the bolt body (see 9e $\sim 9 i$ ). Through the above analysis, it can be seen that the failure of bolt body occurs in the next loading step after the stress reaches the peak value, which is also the stage of stress decrease. On the other hand, there is only one failure in the anchored rock mass with positive Poisson's ratio bolt (see Fig. 10).

When the loading is over, the bearing capacity of the rock strengthened by the positive Poisson's ratio bolt is reduced to 0 , while the rock strengthened by the negative Poisson's ratio bolt still has a certain bearing capacity, which is $82.8 \mathrm{MPa}$. The maximum bearing capacity of the rock reinforced with positive and negative Poisson's ratio bolts is 131.2MPa and 378.2MPa respectively. It can be seen that the addition of a negative Poisson's ratio bolt in the rock can improve the stress state of the rock mass, enhance the bearing capacity of the anchored rock mass, and make up for the defects of the traditional bolt.

As shown in Fig. 11, the stress of point A, B and C of the anchored rock negative Poisson's ratio bolt is greater than that the corresponding points of anchored rock positive Poisson's ratio bolt. This is because the expansion deformation of bolt body increases the friction between the bolt body and the surrounding rock, and the increased friction in turn also limits the displacement of surrounding rock.

Figure 8. Stress curve of two different anchored rock

Figure 9. Failure process of anchored rock with negative Poisson's ratio bolt (The left column is the stress nephogram, the right column is the acoustic emission diagram)

Figure 10. Failure process of anchored rock with positive Poisson's ratio bolt (The left column is the stress nephogram, the right column is the acoustic emission diagram)

Figure 11. Stress comparison curves of point A, B and C of two kinds of anchored rock before loading step 168

\subsection{Acoustic emission characteristic analysis}


When it is loaded to loading step 480, both AE quantity and AE energy of the anchored rock mass with negative Poisson's ratio bolt appear to rise suddenly, reaching the first peak value, and their values are 145 time and $0.099 \mathrm{~J}$ respectively (see Fig. 12 and Fig. 13). When it is loaded to loading step 523, the number and energy of $A E$ increase again, reaching the second peak value, which are 296 time and $0.403 \mathrm{~J}$ respectively. The difference is that the second peak value of stress is lower than the first peak value, while the second peak value of $A E$ quantity and $A E$ energy are both higher than the first peak. This also shows that the $A E$ quantity and $A E$ energy mainly occur in the stress drop stage. The number of AE quantity reaches the peak value for the anchored rock with positive Poisson's ratio bolt when loaded to loading step 166 (see Fig. 14). The peak of AE quantity is also after the stress peak, but the AE energy does not show obvious regularity (see Fig. 15).

It can be seen from Table 3 that the maximum and cumulative values of $A E$ energy of the anchored rock mass with positive Poisson's ratio bolt are $0.00012 \mathrm{~J}$ and $0.00153 \mathrm{~J}$, respectively. The maximum and cumulative value of $A E$ energy of anchored rock with negative Poisson's ratio are much larger than that of anchored rock with negative Poisson's ratio, and the values are $0.40329 \mathrm{~J}$ and $0.71482 \mathrm{~J}$ respectively. Above-mentioned phenomena show that more energy would be absorbed after the negative Poisson's ratio bolt is driven into the rock. That is to say, after adding a negative Poisson's ratio bolt to rock, the negative Poisson's ratio bolt can better protect the integrity of the surrounding rock and prevent the occurrence of geological disasters under the condition of the same geological conditions and load.

Table 3

The number and energy of $A E$ in two different anchored rock after loading

\begin{tabular}{|lllll|}
\hline & $\begin{array}{l}\text { Maximum number } \\
\text { of AE/Time }\end{array}$ & $\begin{array}{l}\text { Total } \\
\text { AE/Time }\end{array}$ & $\begin{array}{l}\text { Maximum AE } \\
\text { energy/J }\end{array}$ & $\begin{array}{l}\text { Total AE } \\
\text { energy/J }\end{array}$ \\
\hline $\begin{array}{l}\text { Anchored rock with negative } \\
\text { Poisson's ratio bolt }\end{array}$ & 296 & 1994 & 0.40329 & 0.71482 \\
\hline $\begin{array}{l}\text { Anchored rock with positive } \\
\text { Poisson's ratio bolt }\end{array}$ & 26 & 76 & 0.00012 & 0.00153 \\
\hline
\end{tabular}

K. Mogi [37] summarized three basic types of $A E$ by analyzing the $A E$ characteristics of different types of materials, namely, main shock type, foreshock-main shock-aftershock type, swarm shock type. According to this $A E$ classification basis, it can be known that the $A E$ quantity and $A E$ energy for the anchored rock with negative Poisson's ratio bolt belong to the main shock type, while the AE quantity and $A E$ energy of the anchored rock with positive Poisson's ratio bolt belong to the main shock type and the swarm shock type respectively.

Figure 12. AE curve of anchored rock with negative Poisson's ratio bolt

Figure 13. AE energy curve of anchored rock with negative Poisson's ratio bolt

Figure 14. AE curve of anchored rock with positive Poisson's ratio bolt 
Figure 15. AE energy curve of anchored rock with positive Poisson's ratio bolt

\section{Conclusion}

(1) Under the action of external force, the expansion deformation of the negative Poisson's ratio bolt prevents the surrounding rock from moving toward the bolt, causing the displacement of the surrounding rock around the bolt with negative Poisson's ratio to be smaller than that around the bolt with positive Poisson's ratio. The numerical experiment results are in good agreement with the actual situation, which also proves the reliability of numerical experiment.

(2) The negative Poisson's ratio bolt has been damaged sequentially from one half of the bolt body to the bolt head under the stress of surrounding rock, the failure mode of rock mass near the bolt failure is tensile failure, and the bolt failure occurs in the stage of stress reduction. When the bolt Poisson's ratio changes from positive to negative, the bearing capacity of anchored mass rock is greatly increased, and the maximum bearing capacity is increased by 2.9 times. The anchored rock with a negative Poisson's ratio bolt still has a certain residual bearing capacity value after loading, which increases the strength of reinforced body. The surrounding rock stress of the negative Poisson's ratio bolt is higher than the surrounding rock stress of the positive Poisson's ratio bolt, which means that the friction between the bolt and the surrounding rock has been increased, the movement of surrounding rock has been restricted, and the integrity of surrounding rock has been protected.

(3) The peak values of AE quantity and AE energy of anchored rock with negative Poisson's ratio bolt occur in the next loading step of the peak bearing capacity. The maximum loadable energy and cumulative energy of anchored rock with negative Poisson's ratio bolt are far greater than that of anchored rock with positive Poisson's ratio bolt, indicating that the reinforcement body with negative Poisson's ratio bolt can absorb more energy and increase the strength and stiffness of anchored rock. In addition, the $A E$ quantity and $A E$ energy of the anchored rock with negative Poisson's ratio bolt belong to the main shock type, the AE quantity and $A E$ energy of the anchored rock with positive Poisson's ratio bolt belong to the main shock type and the swarm shock type respectively.

\section{Declarations}

\section{Conflict of interest statement}

We declare that we have no financial and personal relationships with other people or organizations that can inappropriately influence our work.

\section{Acknowledgements}

This study was supported by the Chinese National Natural Science Foundation (No. 41572249) and the State Key Laboratory for GeoMechanics and Deep Underground Engineering, China University of Mining \& 
Technology (No. SKLGDUEK1825).

\section{References}

1. Hyett AJ, Moosavi M, Bawden WF (2015) Load distribution along fully grouted bolts with emphasis on cable bolt reinforcement[J]. Int J Numer Anal Meth Geomech 20(7):517-544

2. He MC, Xie HP, Peng SP et al (2005) Study on rock mechanics in deep mining engineering[J]. Chin J Rock Mechan Eng 24(16):2803-2813

3. Kim Y, Hossain MS, Lee J. Dynamic Installation of a Torpedo Anchor in Two-layered Clays[J]. Canadian Geotechnical Journal, 2017(2): 446-454

4. Vandermaat D, Saydam S, Hagan PC et al (2016) Examination of rockbolt stress corrosion cracking utilising full size rockbolts in a controlled mine environment[J]. Int J Rock Mech Min Sci 81:86-95

5. Kang H, Wu Y, Gao F et al (2013) Fracture characteristics in rock bolts in underground coal mine roadways[J]. Int J Rock Mech Min Sci 62(5):105-112

6. Jalalifar $\mathrm{H}$ (2006) A new approach in determining the load transfer mechanism in fully grouted bolts[D]. University of Wollongong, Australia

7. He MC, Gong WL, Wang J et al (2014) Development of a novel energy-absorbing bolt with extraordinarily large elongation and constant resistance[J]. Int J Rock Mech Min Sci 67(1):29-42

8. Alderson A, Alderson KL. Proceedings of the Institution of Mechanical Engineers $G$ Journal of Aerospace Engineering[J]. Auxetic materials, 2007, 221: 565-575

9. Yu C, Ji S, Li Q (2016) Effects of porosity on seismic velocities, elastic moduli and Poisson's ratios of solid materials and rocks[J]. J Rock Mech Geotech Eng 8(1):35-49

10. Wan H, Ohtaki H, Kotosaka S et al (2004) A study of negative Poisson's ratios in auxetic honeycombs based on a large deflection model[J]. European Journal of Mechanics: A /Solids 23(1):95-106

11. Horrigan EJ, Smith CW, Scarpa FL et al (2009) Simulated optimization of disordered structures with negative Poisson's ratios[J]. Mech Mater 41(8):919-927

12. Gaspar N (2010) A granular material with a negative Poisson's ratio[J]. Mech Mater 42:673-677

13. Shi ZC, Fan RH, Zhang ZD et al (2012) Random composites of nickel networks supported by porous alumina toward double negative materials[J]. Adv Mater 24(17):2349-2352

14. Liu YP, Hu H (2010) A review on auxetic structures and polymeric materials[J]. Scientific Research Essays 5(10):1052-1063

15. Saxena KK, Das R, Calius EP (2016) Three decades of auxetics research materials with negative Poisson's ratio: A Review[J]. Adv Eng Mater 18:1847-1870

16. Evans KE (2010) Auxetic Materials: Functional Materials and Structures from Lateral Thinking! [J]. Adv Mater 12(9):617-628

17. Critchley R, Corni I, Wharton JA et al (2013) A review of the manufacture, mechanical properties and potential applications of auxetic foams[J]. Physica Status Solidi 250(10):1963-1982 
18. Li JW, Qiao JG, Fu X et al (2019) Research Progress on Material/Structure and Mechanical Properties of Energy-absorbing Bolt Used in Ground Anchorage[J]. Materials reports 33(5):1567-1574

19. Lakes R (1987) Foam structures with a negative Poisson's ratio[J]. Science 235(4792):1038-1040

20. Martz EO, Lee T, Lakes R et al (1996) Re-entrant transformation methods in closed cell foams [J]. Cellular polymers 15(4):229-249

21. Chen F, Tang CA, Sun XM et al (2019) Supporting characteristics analysis of constant resistance bolts under coupled static-dynamic loading[J]. J Mt Sci 16(05):217-226

22. Tang CA, Chen F, Sun XM et al (2018) Numerical analysis for support mechanism of constantresistance bolts[J]. Chinese Journal of Geotechnical Engineering 40(12):2281-2288

23. Grima JN, Gatt R, Alderson A et al (2005) On the potential of connected stars as auxetic systems[J]. Mol Simul 31(13):925-935

24. Alderson KL, Alderson A, Webber RS et al (1998) Evidence for uniaxial drawing in the fibrillated microstructure of auxetic microporous polymers[J]. J Mater Sci 17(16):1415-1419

25. Ravirala N, Alderson KL, Davies PJ et al (2006) Negative Poisson's ratio polyester fibers[J]. Textile research journal 76(7):540-546

26. Alderson KL, Andrew A, Smart G et al (2002) Auxetic polypropylene fibres: Part I -Manufacture and characterisation[J]. Plastics rubber composites 31(8):344-349

27. Lakes R (1993) Materials with structural hierarchy[J]. Nature 361(6412):511-515

28. Miller W, Hook PB, Smith CW et al (2009) The manufacture and characterisation of a novel, low modulus, negative Poisson's ratio composite[J]. Composites Science Technology 69(5):651-655

29. Wojciechowski KW (1989) Two-dimensional isotropic system with a negative Poisson's ratio[J]. Phys Lett A 137(1):60-64

30. Grima JN, Gatt R, Alderson A et al (2006) An alternative explanation for the negative Poisson's ratios in a-cristobalite[J]. Materials Science Engineering 423:219-224

31. Gercek H (2007) Poisson's ratio values for rocks. Int J Rock Mech Min Sci 44:1-13

32. Tang CA, Yang WT, Fu YF et al (1998) A new approach to numerical method of modelling geological processes and rock engineering problems-continuum to discontinuum and linearity to nonlinearity[J]. Eng Geol 49(3-4):207-214

33. Tang CA (1997) Numerical simulation of progressive rock failure and associated seismicity[J]. Int J Rock Mech Min Sci 34(2):249-261

34. Tang CA, Kaiser PK (1998) Numerical simulation of cumulative damage and seismic energy release in unstable failure of brittle Rock-part I. Fundamentals[J]. Int J Rock Mech Min Sci 35(2):113-121

35. Tang CA (2003) Numerical experiments of rock failure process[M]. Science Press, Beijing. (in Chinese)

36. Zhang JX, Tang CA, Liang ZZ et al (2007) Numerical simulation of failure process of reinforced concrete specimen under uniaxial tension[J]. Chinese Journal of Computational Mechanics 24(4):454-458. (in Chinese) 


\section{Figures}

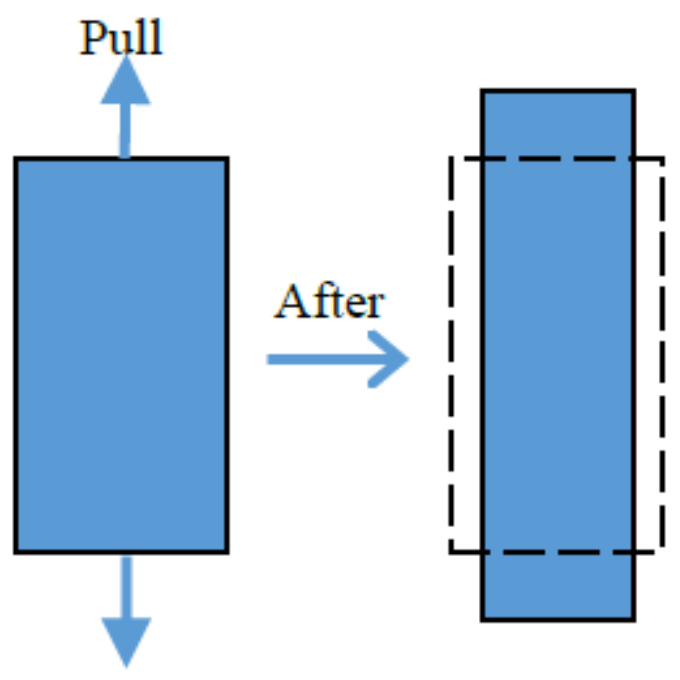

Pull

(a) Positive Poisson ratio material
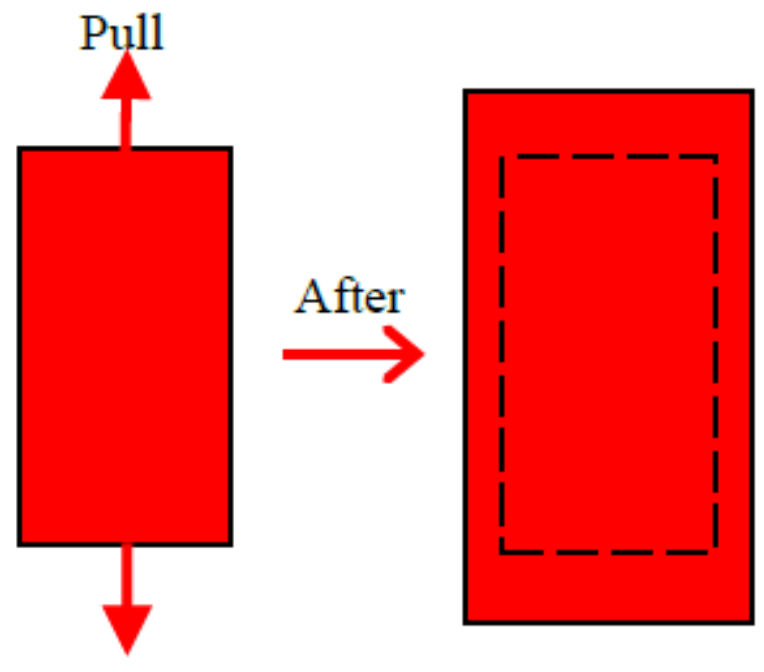

Pull

\section{Figure 1}

The deformation of axial tension material

\section{Honeycombs}

e.g. polymer, metal and ceramic

Polymeric and metal foams

e.g. polyurethane and copper

Molecular Auxetics

e.g. iron pyrites and arsenic

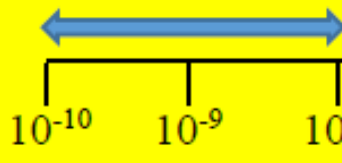

Microporous Polymers

e.g. ptfe and uhmwpe
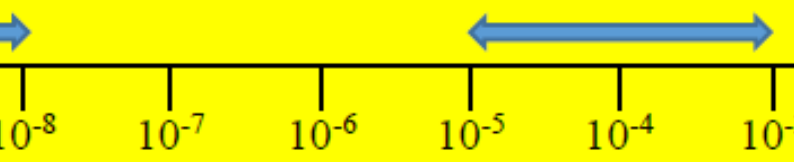

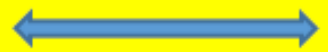




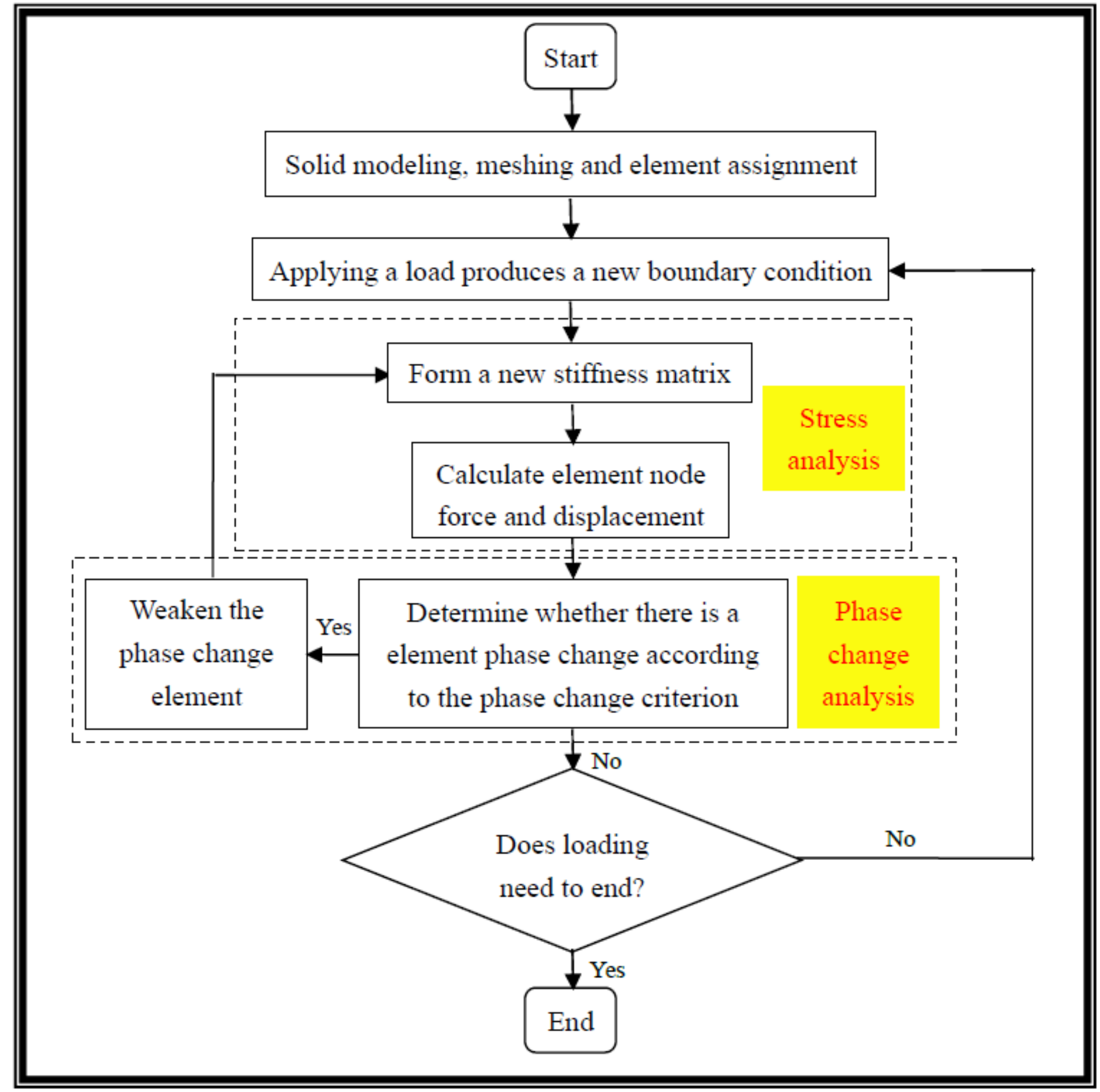

Figure 3

RFPA software workflow picture 


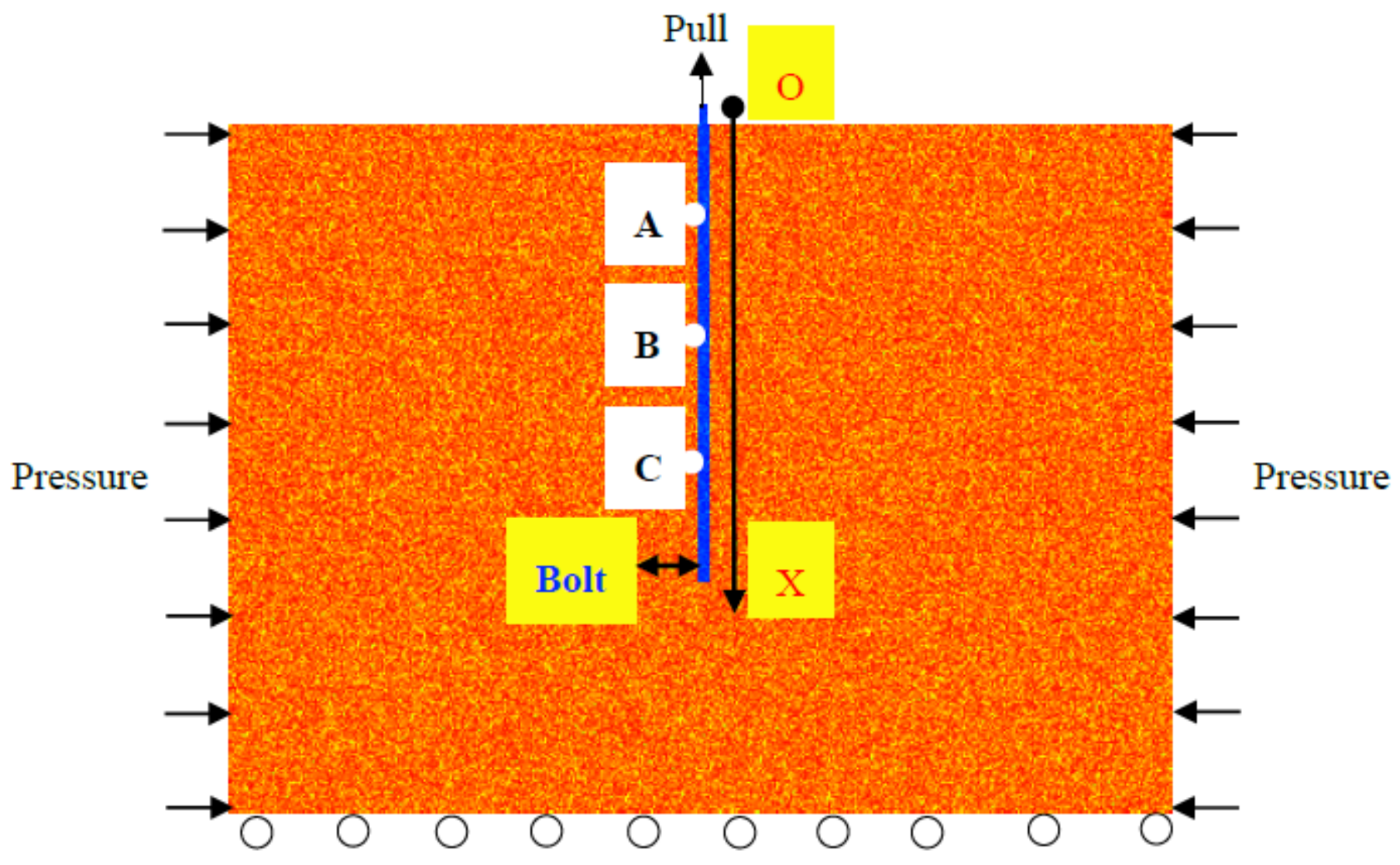

Figure 4

Numerical model 


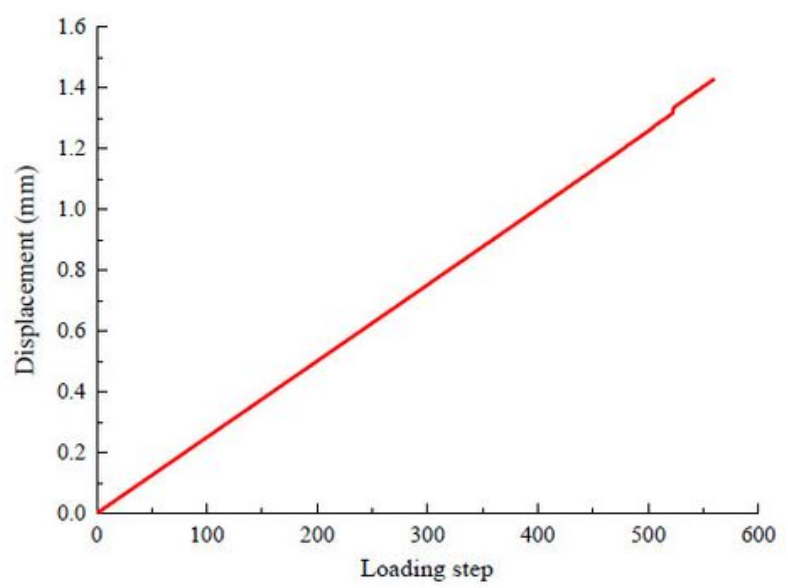

(a) Point $\mathrm{A}$

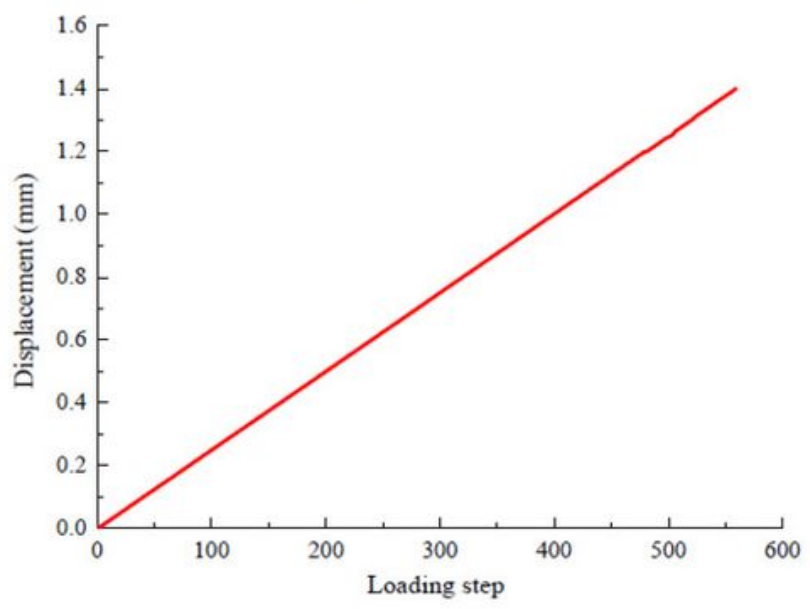

(b) Point B

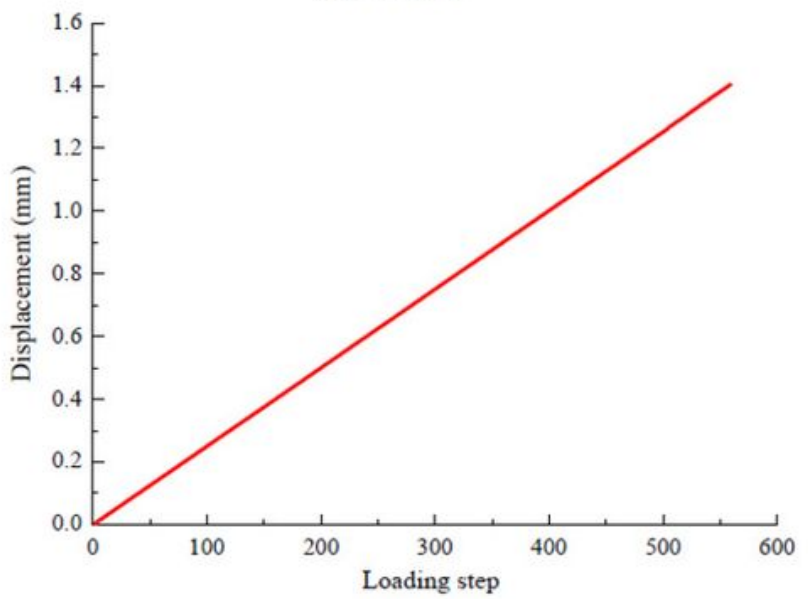

(c) Point $\mathrm{C}$

\section{Figure 5}

Displacement curves of points $A, B$ and $C$ of anchored rock with negative Poisson's ratio bolt 


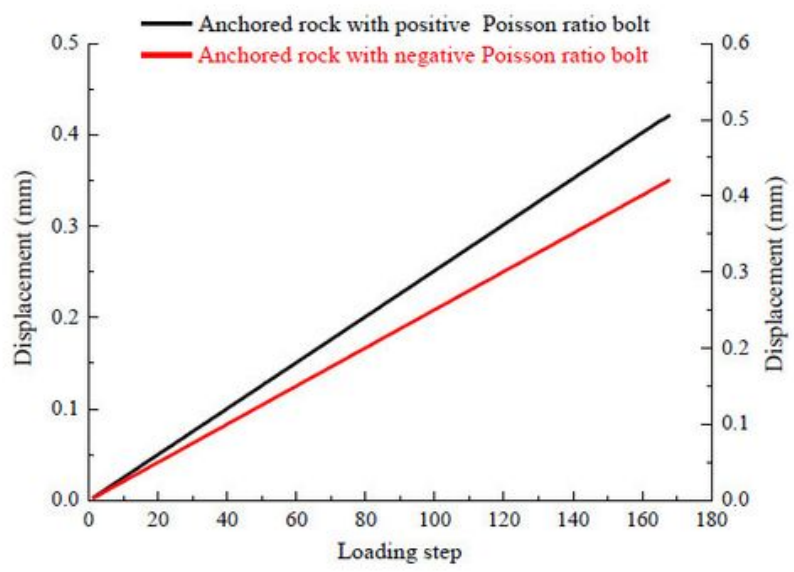

(a) Point A

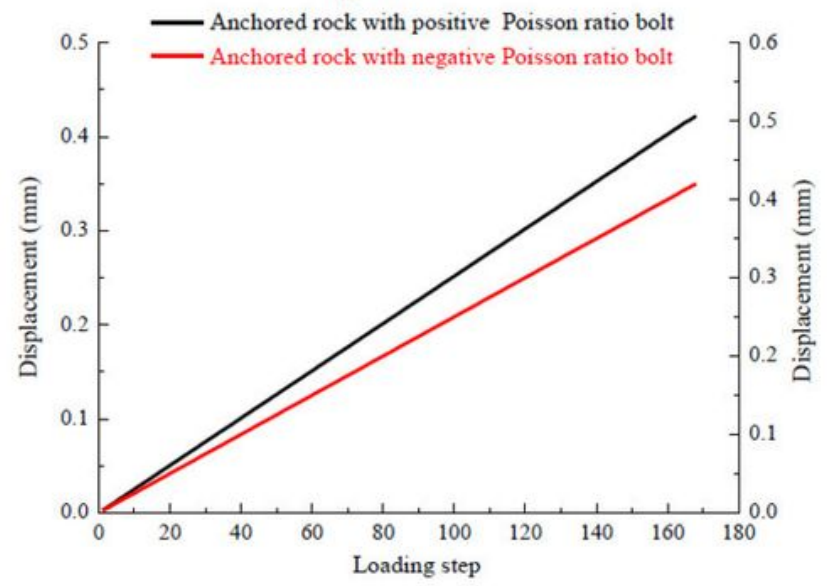

(b) Point B

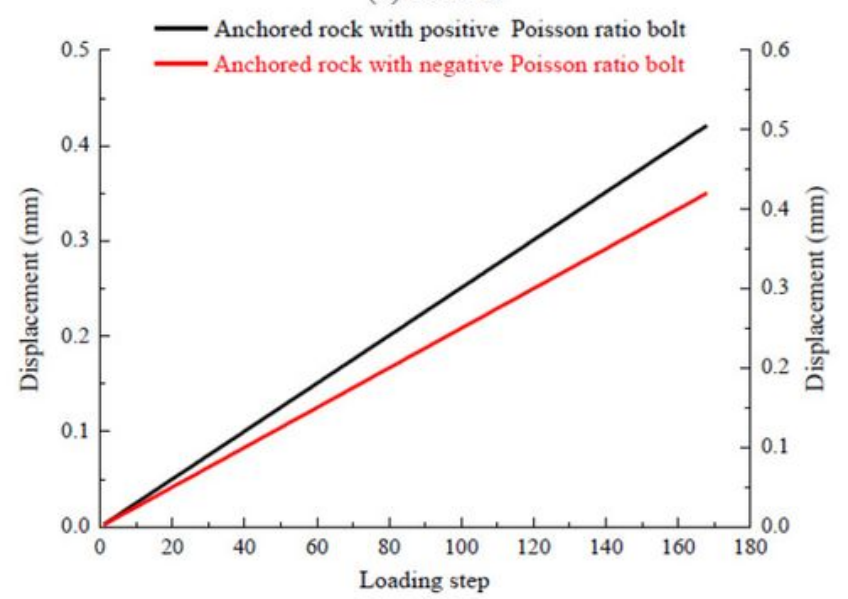

(c) Point $\mathrm{C}$

Figure 6

Displacement comparison curves of points A, B and C of two kinds of anchored rock before loading step 168 


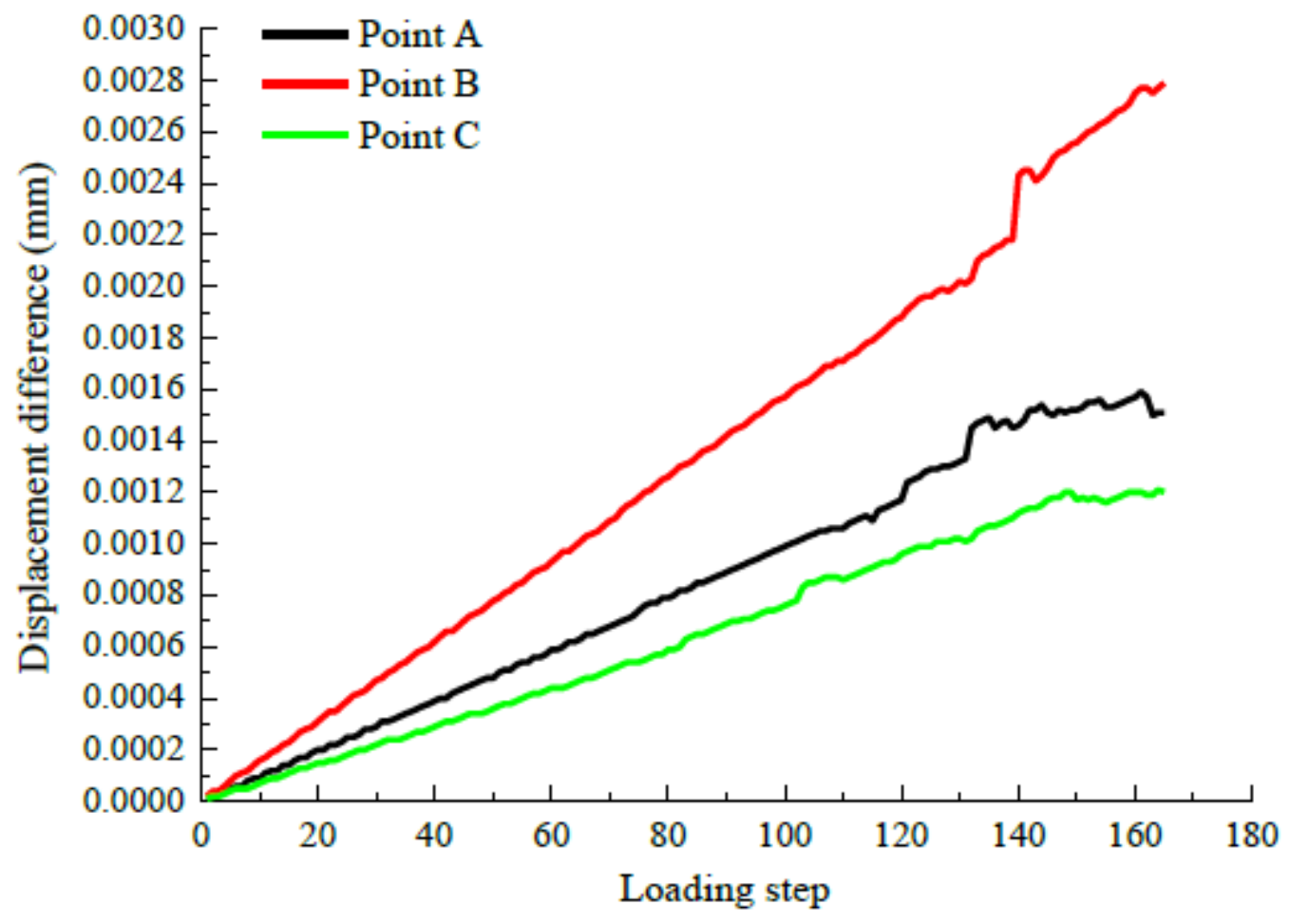

Figure 7

Displacement difference curve of points A, B and C of two kinds of anchored rock

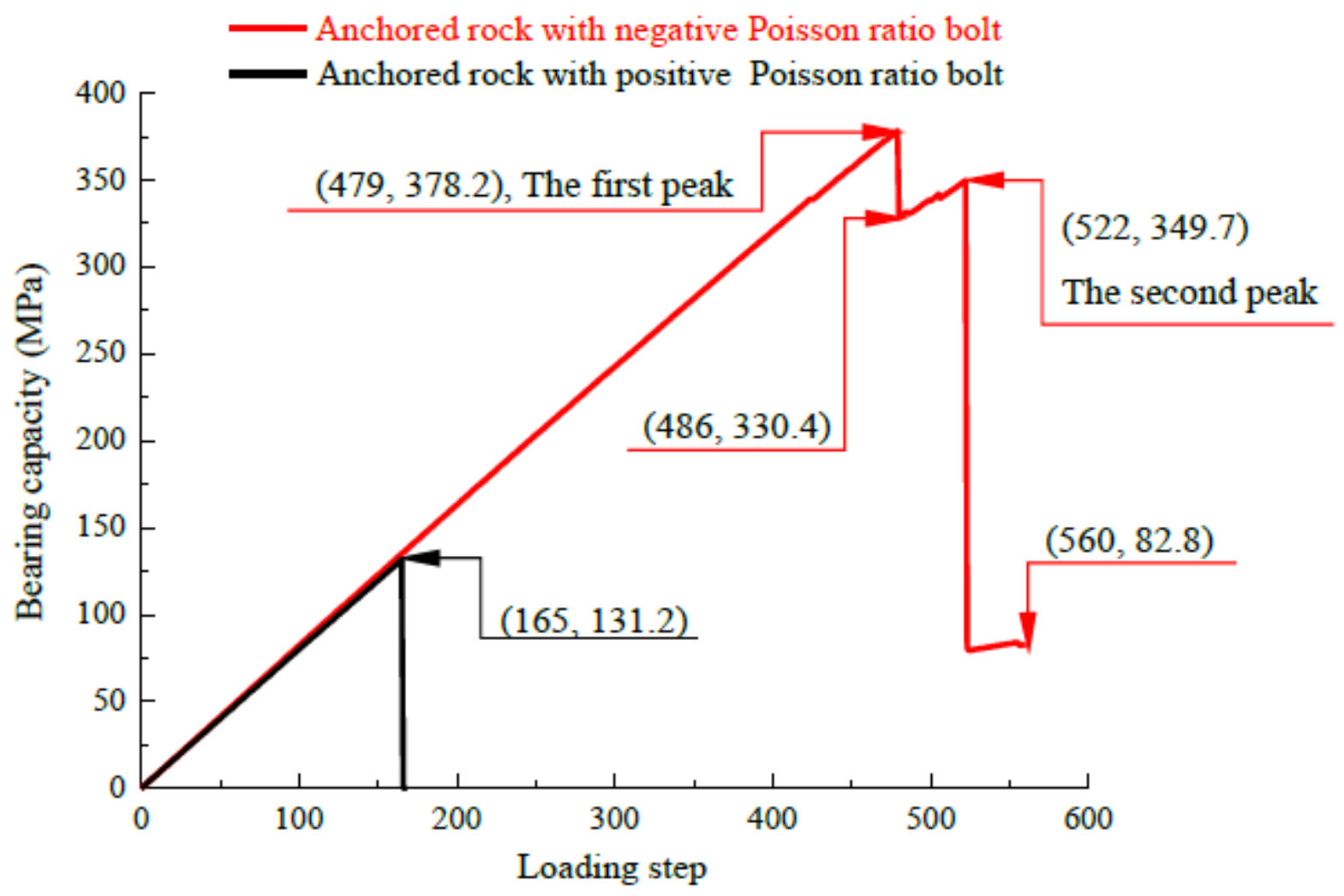


Figure 8

Stress curve of two different anchored rock
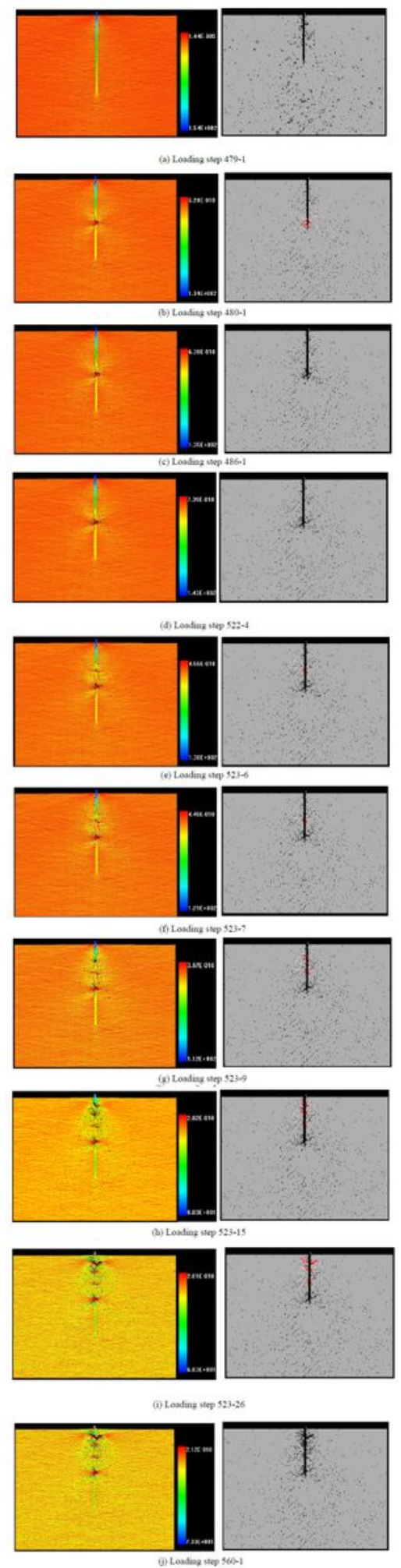

Figure 9

Failure process of anchored rock with negative Poisson's ratio bolt (The left column is the stress nephogram, the right column is the acoustic emission diagram) 

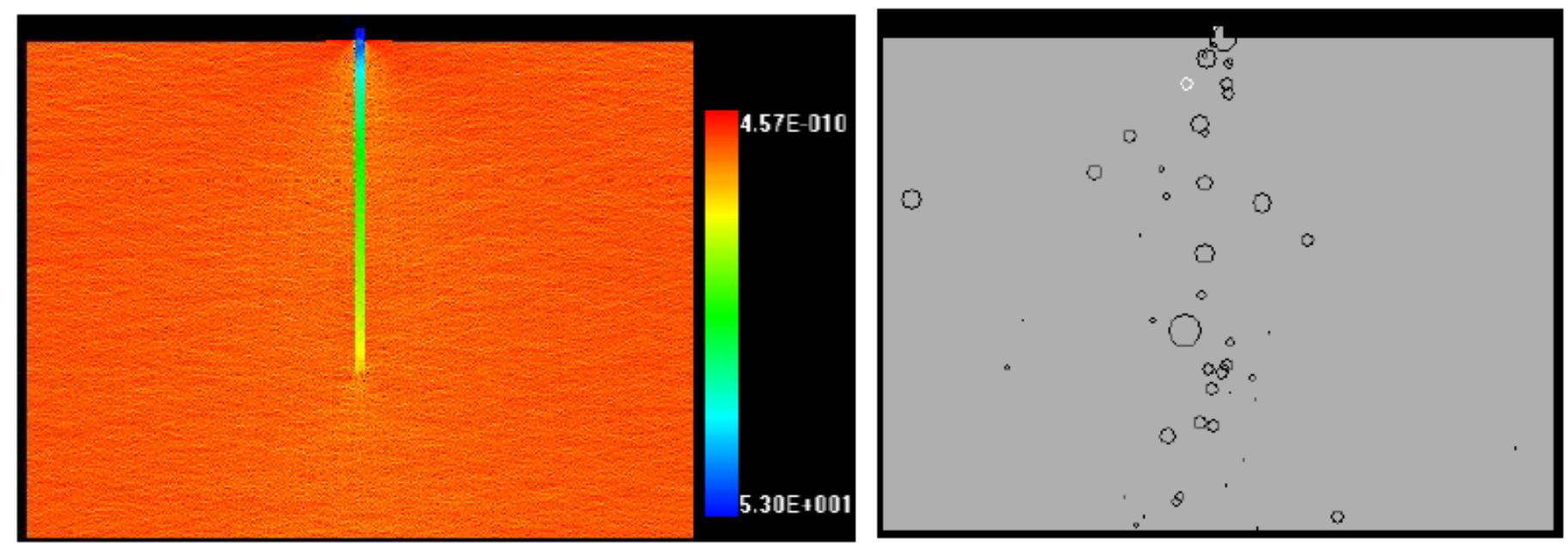

(a) Loading step $165-1$
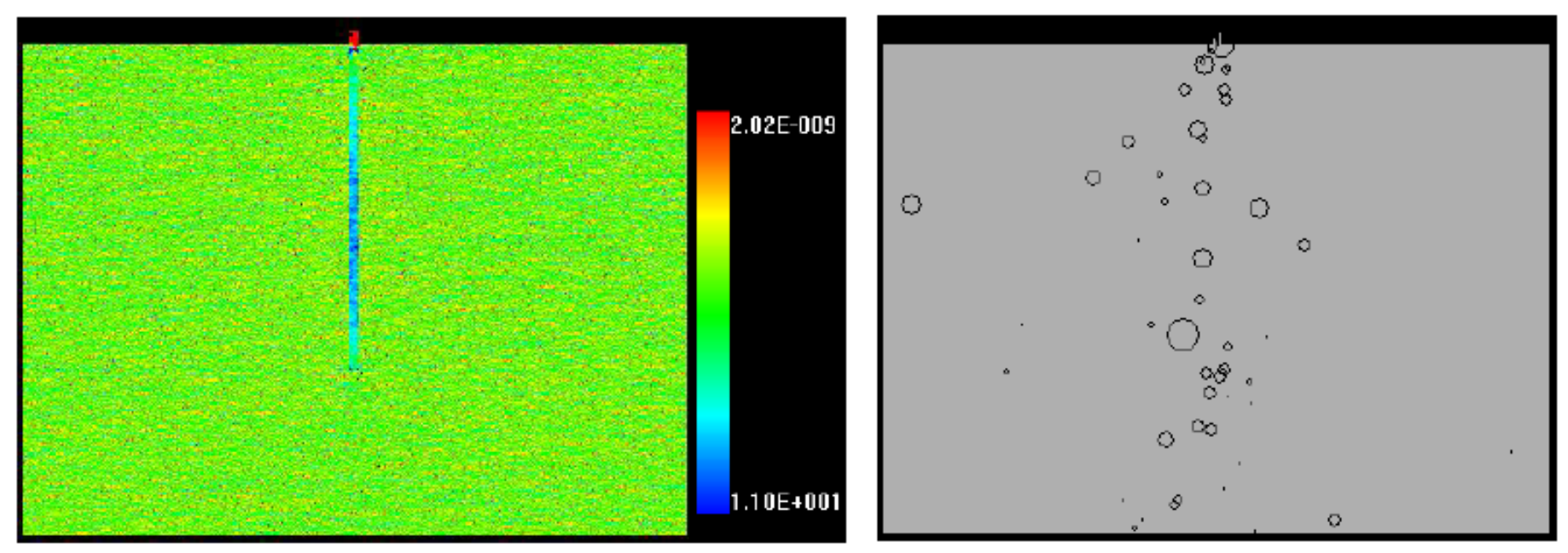

(b) Loading step 168-1

Figure 10

Failure process of anchored rock with positive Poisson's ratio bolt (The left column is the stress nephogram, the right column is the acoustic emission diagram) 


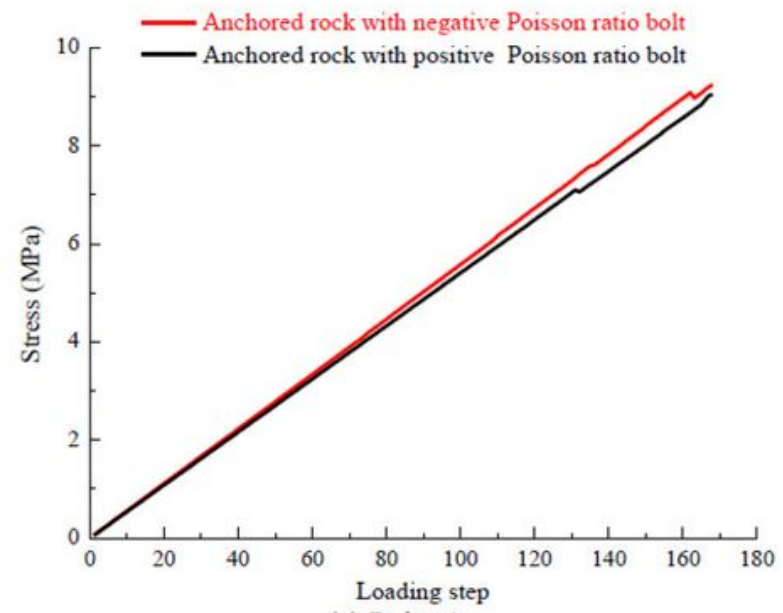

(a) Point A

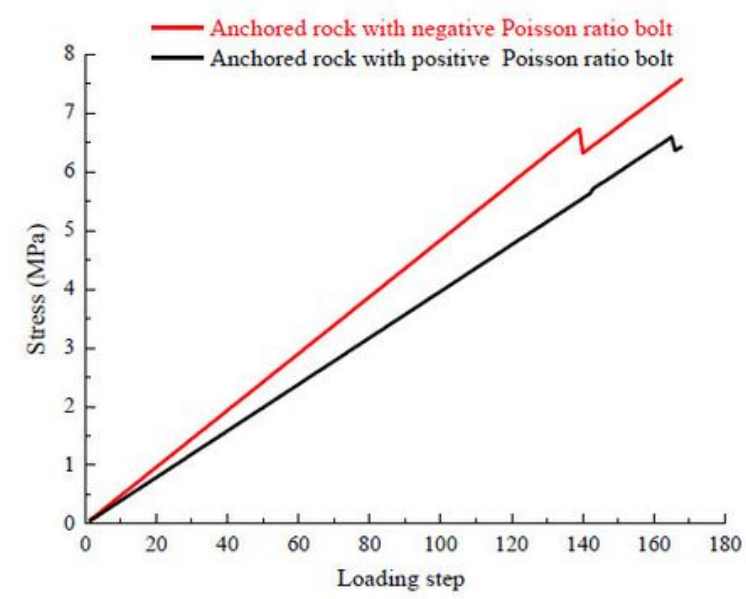

(b) Point $\mathrm{B}$

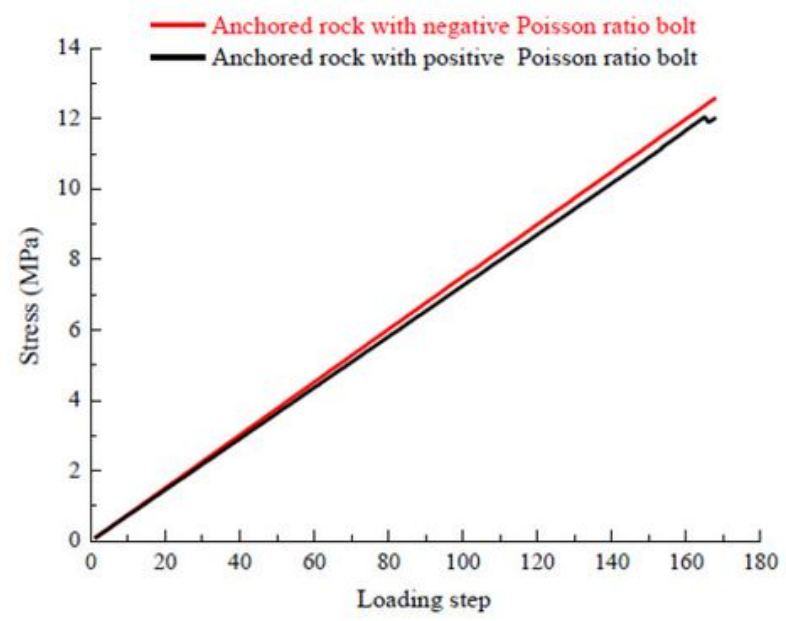

(c) Point $\mathrm{C}$

\section{Figure 11}

Stress comparison curves of point A, B and C of two kinds of anchored rock before loading step 168 


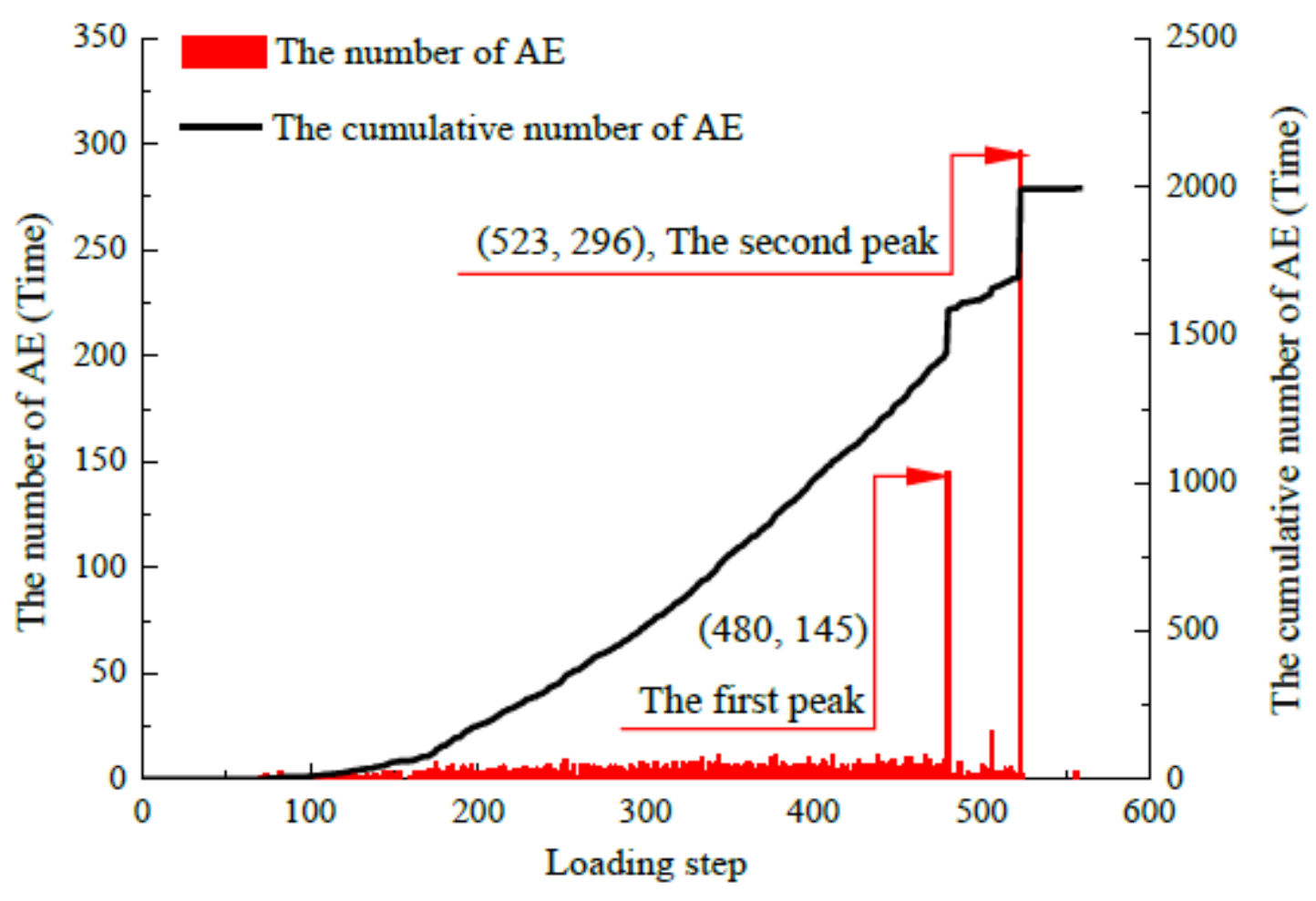

Figure 12

AE curve of anchored rock with negative Poisson's ratio bolt

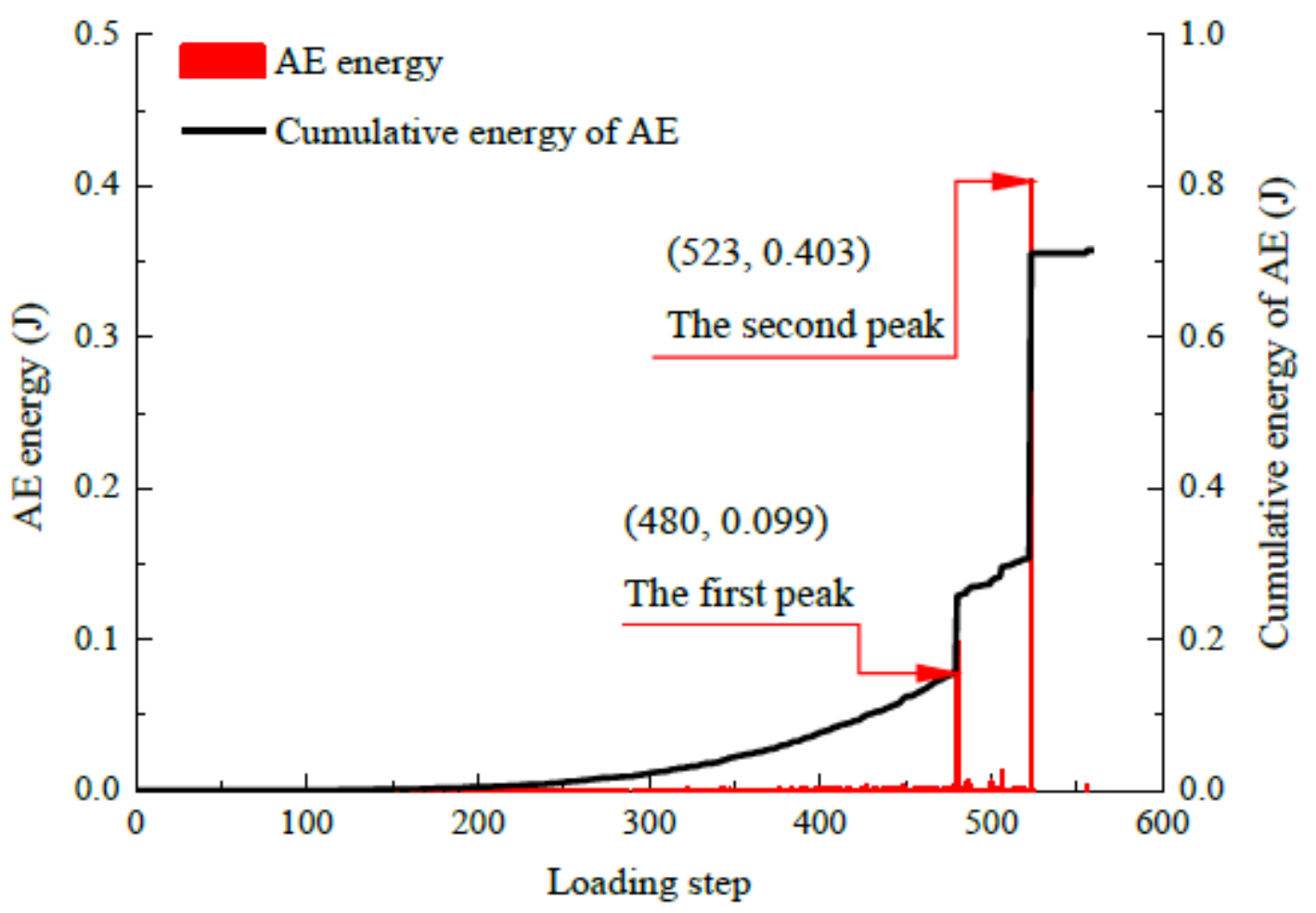


Figure 13

AE energy curve of anchored rock with negative Poisson's ratio bolt

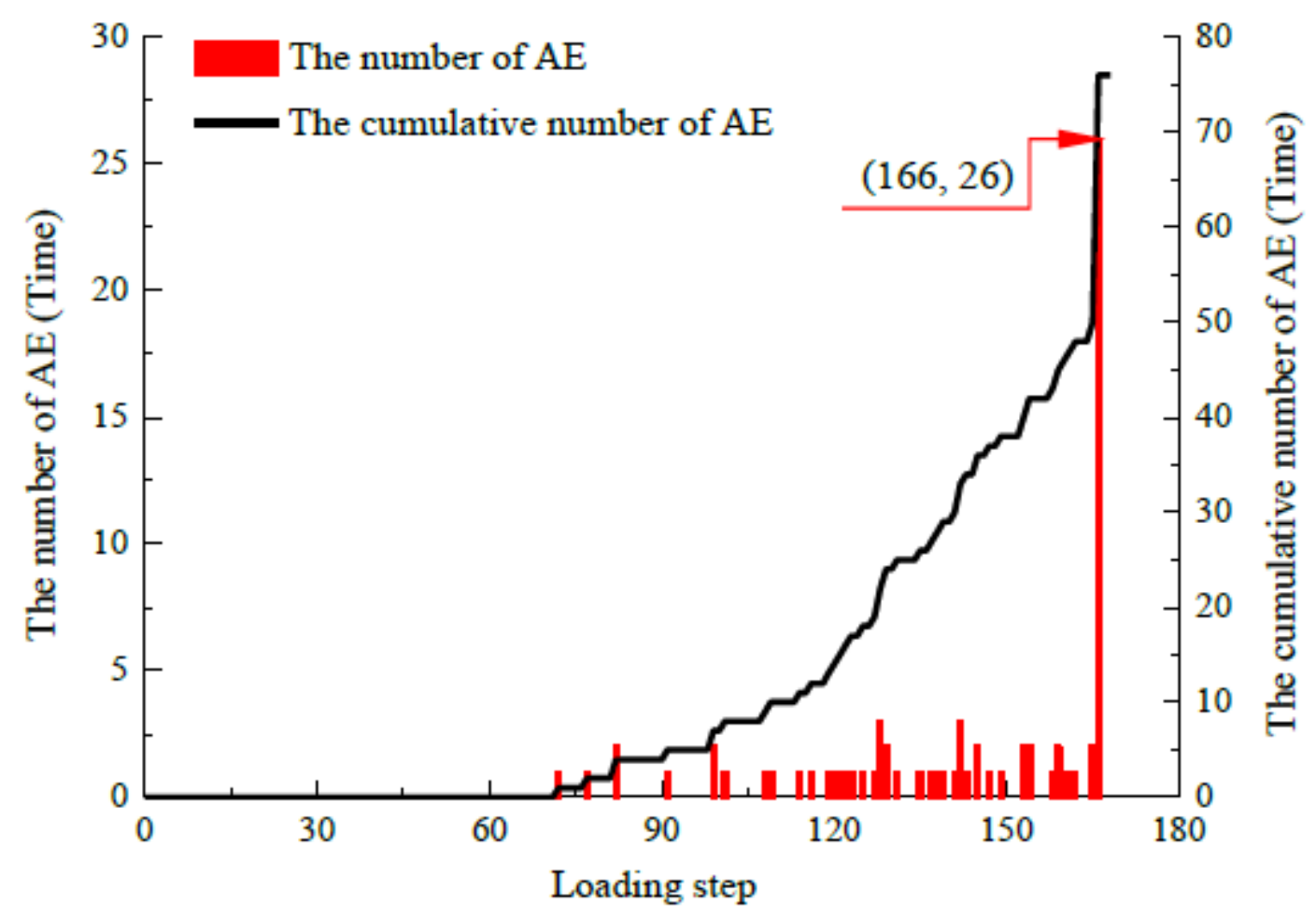

Figure 14

AE curve of anchored rock with positive Poisson's ratio bolt 


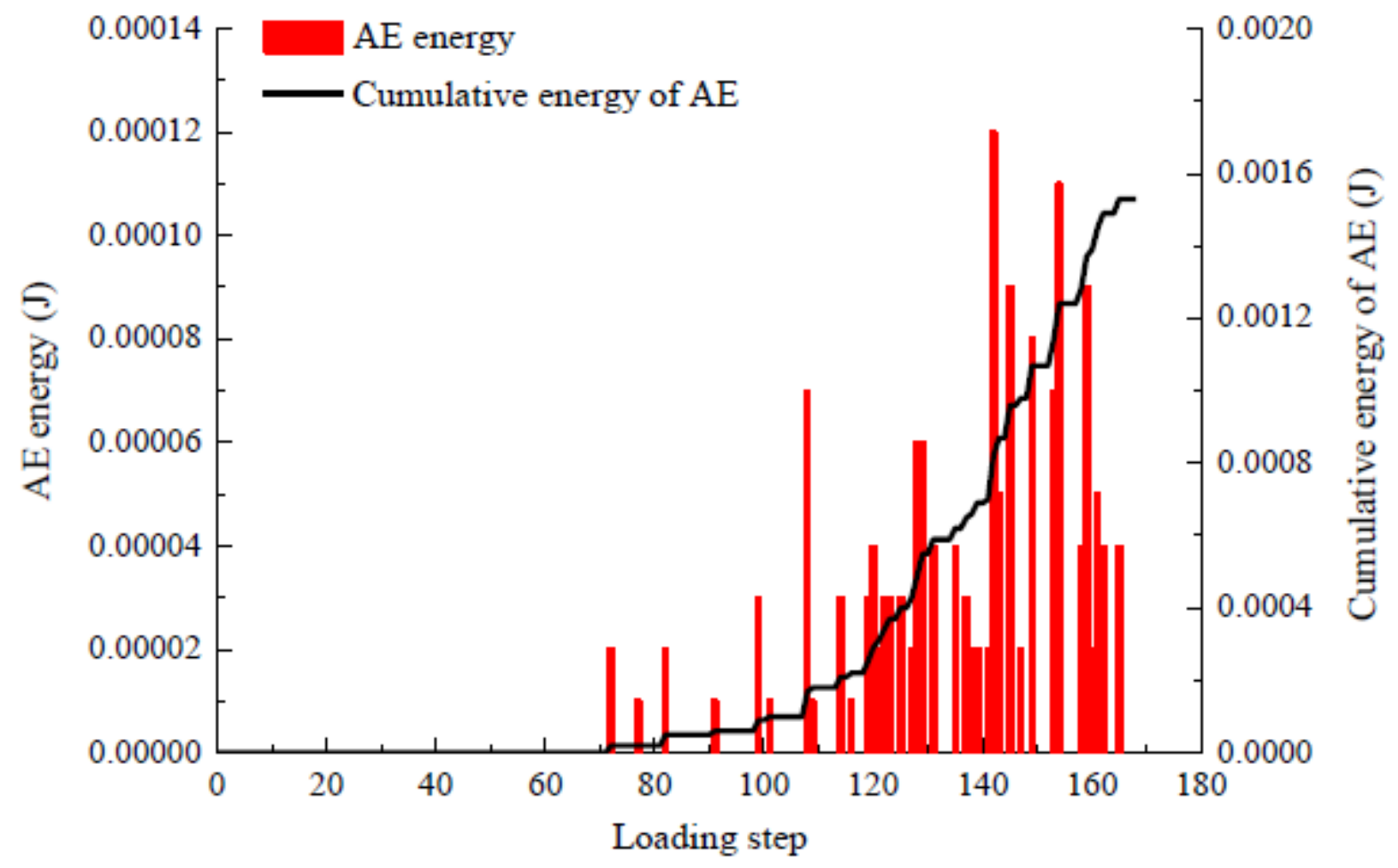

Figure 15

AE energy curve of anchored rock with positive Poisson's ratio bolt 